\title{
Efeitos das políticas econômicas restritivas sobre a condição de saúde dos brasileiros
}

\author{
Milton Aparecido de Souza JUNIOR ${ }^{(1)}$ \\ Áquilas Nogueira MENDES(1)
}

Recebido: 28 jan 2019 Aceito: 10 fev 2019

Autor de correspondência: miltonjnior@gmail.com

Conflito de interesses: Os autores declaram não haver nenhum interesse profissional ou pessoal que possa gerar conflito de interesses em relação a este manuscrito.
${ }^{(1)}$ Faculdade de Saúde Pública, Universidade de São Paulo - USP, São Paulo, SP, Brasil.

\section{Resumo}

Em 2015, o Brasil começou a implementar uma política fiscal restritiva, seguindo o caminho adotado por países europeus após a crise capitalista internacional de 2008. As políticas econômicas restritivas caracterizam-se por escolhas que exigem grandes sacrifícios da população, seja porque aumentam a carga tributária, seja pela implementação de medidas que restringem a oferta de benefícios, bens e serviços públicos em razão de cortes de despesas públicas ou da realização de reformas estruturais, afetando de forma significativa os estratos mais vulneráveis. A partir da experiência de países da União Europeia, onde o corte de gastos sociais e a realização de reformas econômicas estruturais diminuíram a capacidade de responder efetivamente à demanda por serviços públicos, uma recente publicação do Centro Brasileiro de Estudos da Saúde revelou que a redução do gasto do governo com proteção social tem sido também associada ao aumento da pobreza e da desigualdade, com importantes consequências para a saúde das populações. Com base na literatura científica internacional, as consequências das crises econômicas para as condições sociais e de saúde das populações afetadas já podem ser minimamente relacionadas, por exemplo, à piora da saúde mental, aumentando a prevalência de depressão e ansiedade, aumento das taxas de suicídio, aumento de doenças crônicas não transmissíveis e de algumas doenças infectocontagiosas, piora no acesso aos serviços de saúde por barreiras econômicas, entre outros problemas. Os pesquisadores David Stuckler e Sanjay Basu também enfatizam que as políticas econômicas restritivas têm ainda efeito devastador sobre a saúde das populações, não só em indicadores de impacto, como o reaparecimento de certas doenças, tais como a desnutrição e algumas doenças infecciosas, mas igualmente em indicadores de estrutura e processo, como a razão médico/população e o tempo interconsultas. No Brasil, análise recente do Centro de Estudos Estratégicos da Fiocruz também aponta para alguns efeitos negativas das restrições econômicas em políticas públicas, principalmente a partir de 2015, como o aumento da taxa de desocupação da força de trabalho, a queda do número de beneficiários de planos de saúde, a redução do gasto em ações e serviços públicos de saúde (ASPS), a queda do número de leitos de internação no SUS, entre outros. Trata-se, portanto, de uma reflexão pertinente e oportuna sobre o futuro do Brasil à luz da conjuntura atual, isto é, em um momento de crise política; de vigência da Emenda 
Constitucional 95/2016, que congelou as despesas primárias da União, em termos reais, por 20 anos; de reemergência de doenças consideradas erradicadas, como sarampo, poliomelite e difteria; e de aumento na taxa de mortalidade infantil, que interrompe um ciclo de queda contínua que já durava 26 anos. Objetivo: Identificar a descrição na literatura nacional dos efeitos das políticas econômicas restritivas sobre os principais indicadores das condições de saúde dos brasileiros. Método: Trata-se de uma revisão integrativa da literatura, com uma abordagem bibliográfica e documental de produções científicas que tenham avaliado os possíveis efeitos das políticas econômicas restritivas no Brasil sobre os principais indicadores das condições de saúde dos brasileiros. Foi realizada pesquisa a partir das bases de dados da Biblioteca Virtual em Saúde Pública - BVS, tais como a Literatura Latino-Americana e do Caribe em Ciências da Saúde - LILACS e Sistema Online de Busca e Análise de Literatura Médica (MEDLINE). A definição de descritores para a busca foi realizada a partir da pergunta de pesquisa "o que a literatura científica apresenta acerca dos impactos das políticas econômicas restritivas sobre os indicadores das condições de saúde dos brasileiros?", permitindo a formulação das sintaxes para encontrar literatura adequada para revisão proposta. A busca bibliográfica baseou-se na técnica de funil, combinando-se diversos descritores relacionados ao tema e utilizando-se as sintaxes necessárias para refinar a busca. A composição sintática realizada do tema parte da compreensão de três eixos temáticos de interesse, identificados a partir da pergunta da pesquisa, quais sejam: (i) políticas econômicas restritivas; (ii) Indicadores; e (iii) condições de saúde. Para cada um deles foram buscados descritores específicos na plataforma http://decs.bvs.br, verificando a aplicabilidade a partir das respectivas definições e utilizando pré-buscas. Após a conexão dos descritores relevantes, por meio da utilização do operador booleano $O R$, optou-se por unir os conjuntos de descritores relacionados a indicadores e condições de saúde (iii $O R$ iv), visto que, notadamente, ambos são influenciados pelo contexto político e econômico. Sendo assim, atende a esse requisito a busca (i) $A N D$ (ii $O R$ iii) a seguinte sintaxe: (mh:("Politica Fiscal" $O R$ "Politica Financeira" $O R$ "Politica de Saude" $O R$ "Politicas Publicas de Saude" $O R$ "Sistema Unico de Saude" $O R$ "Recessão Econômica" $O R$ "Economia da Saude" $O R$ "Recursos Financeiros em Saude" $O R$ "Financiamento da Assistencia a Saude" $O R$ "Gastos em Saude" $O R$ "Setor Público")) $A N D$ (mh:("Indicadores Basicos de Saude" $O R$ "Indicadores de Morbimortalidade" $O R$ "Determinantes Sociais da Saude" $O R$ "Indicadores Economicos" $O R$ "Impactos na Saúde" $O R$ "Nivel de Saude" $O R$ "Condicoes Sociais" $O R$ "Disparidades nos Niveis de Saude")). Considerações finais: a busca inicial resultou em um total de 5.911 resultados identificados até 05/01/2019, sobre os quais foram aplicados três filtros de identificação para a leitura exploratória das obras bibliográficas: disponibilidade do texto completo, País/Região como assunto (Brasil) e ano de publicação (2009 a 2018, na medida em que este abrange os dez anos subsequentes à crise financeira internacional deflagrada pela falência do banco de investimentos Lehman Brothers). Após este procedimento, a busca resultou em 135 publicações elegíveis. Com objetivo de 
verificar quais artigos consultados têm relação com o objetivo geral desta pesquisa, foram aplicados ainda alguns critérios de inclusão e exclusão. Deste modo, foram excluídas 20 publicações por repetição; cinco por não estarem disponíveis para acesso público nas bases de dados; e 89 por não apresentarem referência direta ao objeto da pesquisa no resumo; restando 21 publicações incluídas para análise na íntegra. Nota-se, a partir de uma análise destes estudos que 17 são artigos e quatro teses; 13 publicações estão em língua portuguesa e oito em inglês; tendo sido publicados nos anos de 2009 (2); 2010 (2); 2011 (0); 2012 (2); 2013 (1); 2014 (5); 2015 (2); 2016 (2); 2017 (3) e 2018 (2).

Descritores: Política de Saúde; Recessão Econômica; Economia da Saúde; Financiamento da Assistência à Saúde; Impactos na Saúde. 